This item was submitted to Loughborough's Research Repository by the author.

Items in Figshare are protected by copyright, with all rights reserved, unless otherwise indicated.

\title{
The effects of a high-protein diet on markers of muscle damage following exercise in active older adults: a randomized, controlled trial
}

PLEASE CITE THE PUBLISHED VERSION

https://doi.org/10.1123/ijsnem.2020-0113

\section{PUBLISHER}

Human Kinetics

VERSION

AM (Accepted Manuscript)

\section{PUBLISHER STATEMENT}

Accepted author manuscript version reprinted, by permission, from International Journal of Sport Nutrition and Exercise Metabolism, 2020, 30 (5), 323-329, https://doi.org/10.1123/ijsnem.2020-0113. @ Human Kinetics, Inc.

\section{LICENCE}

CC BY-NC-ND 4.0

\section{REPOSITORY RECORD}

Clifford, Tom, Eleanor J Hayes, Jadine H Scragg, Guy Taylor, Kieran Smith, Kelly A Bowden Davies, and Emma J Stevenson. 2020. "The Effects of a High-protein Diet on Markers of Muscle Damage Following Exercise in Active Older Adults: A Randomized, Controlled Trial”. Loughborough University. https://hdl.handle.net/2134/12681413.v1. 
1 Title: The effects of a high protein diet on markers of muscle damage following exercise in

2 active older adults: a randomized, controlled trial

3

\section{Authors:}

5 Tom Clifford ${ }^{1,2}$, Eleanor J. Hayes ${ }^{1}$, Jadine H. Scragg ${ }^{1}$, Guy Taylor ${ }^{1}$, Kieran Smith $^{1}$, Kelly A.

6 Bowden Davies ${ }^{1}$, Emma J. Stevenson ${ }^{1}$

7

8 Affiliations:

$9 \quad{ }^{1}$ Population Health Sciences Institute, Newcastle University, Newcastle, UK.

$10{ }^{2}$ School of Sport, Exercise and Health Sciences, Loughborough University, Loughborough, 11 UK.

12 Running head: Protein and exercise recovery in older adults

13 Address for correspondence:

14 Tom Clifford

15 School of Sport, Exercise and Health Sciences

16 Loughborough University

17 Loughborough

18 LE11 3TU

19 UK

20

Tel: +44 (0) 1509228181

Email: t.clifford@lboro.ac.uk

22 
Abstract

27

Purpose: This study examined whether a higher protein diet following strenuous exercise can alter markers of muscle damage and inflammation in older adults. Methods: Using a doubleblind, independent group's design, 10 males and 8 females (age, $57 \pm 4$ years; mass, $72.3 \pm 5.6$ $\mathrm{kg}$; height, $1.7 \pm 6.5 \mathrm{~m}$ ) were supplied with a higher protein (HP; $2.50 \mathrm{~g} \cdot \mathrm{kg} \cdot \mathrm{day}^{-1}$ ) or moderate protein (MP; $1.25 \mathrm{~g} \cdot \mathrm{kg} \cdot \mathrm{day}^{-1}$ ) diet for $48 \mathrm{~h}$ after 140 squats with $25 \%$ of their body mass. Maximal isometric voluntary contractions (MIVC), muscle soreness, creatine kinase (CK), brief assessment of mood adapted (BAM+), and inflammatory markers were measured pre, 24 and 48 h post-exercise. Results: MIVC decreased post-exercise $(P=0.001, \eta p 2: 0.421)$ but did not differ between groups $(\mathrm{P}=0.822, \eta \mathrm{p} 2: 0.012)$. Muscle soreness peaked at $24 \mathrm{~h}$ post in MP $(44 \pm 30 \mathrm{~mm})$ and $48 \mathrm{~h}$ post in HP $(70 \pm 46 \mathrm{~mm})(\mathrm{P}=0.005 ; \eta p 2: 0.282)$; however, no group differences were found $(\mathrm{P}=0.585 ; \eta p 2$ : 0.083$)$. Monocytes and lymphocytes significantly decreased post-exercise and eosinophils increased 24 h post $(\mathrm{P}<0.05)$ but neutrophils, $\mathrm{CK}$, interleukin-6, c-reactive protein, monocyte-chemotactic protein-1 and BAM+ were unchanged by exercise or the intervention $(\mathrm{P}>0.05)$. Conclusion: In conclusion, $2.50 \mathrm{~g} \cdot \mathrm{kg} \cdot \mathrm{day}^{-1}$ of protein is not more effective than $1.25 \mathrm{~g} \cdot \mathrm{kg} \cdot \mathrm{day}^{-1}$ for attenuating indirect markers of muscle damage and inflammation following strenuous exercise in older adults.

Key words: High intensity exercise; whey protein; immunity. 


\section{Introduction}

High intensity exercise, especially that encompassing repetitive eccentric-muscle contractions, often leads to muscle soreness, inflammation and a drop in neuromuscular function that can persist for several days (Hyldahl \& Hubal, 2014; Warren, Ingalls, Lowe, \& Armstrong, 2002). These symptoms are thought to be the result of disruption to the excitation-contraction coupling process and/or ultrastructural damage to muscle fibres and the surrounding extracellular matrix (Hyldahl \& Hubal, 2014; Warren et al., 2002).

There are several factors that influence the magnitude of force loss and muscle soreness following exercise, including the type, volume, intensity and novelty of the bout (Hyldahl \& Hubal, 2014). An important, but only more recently considered factor, is age; indeed, it has been shown older individuals ( $\geq 50$ years of age) recover from exercise at a slower rate than their younger counterparts (Brisswalter \& Nosaka, 2013; Doering, Jenkins, et al., 2016; Easthope et al., 2010). The reasons for this are likely multi-factorial, but one recent study suggested that the so called 'anabolic resistance' associated which old age, characterized by an impaired muscle protein synthetic response, is likely to be an important factor. Indeed, Doering et al., (Doering, Reaburn, Borges, Cox, \& Jenkins, 2017) found that in response to $20 \mathrm{~g}$ of whey protein, myofibril fractional synthetic rate (FSR) was $\sim 12 \%$ lower in older ( $\sim 53$ years old) versus younger ( $\sim 27$ years old) adults in the 3 days following a bout of muscle-damaging exercise. These findings were associated with poorer performance during a cycling time trial $10 \mathrm{~h}$ after the exercise bout, suggesting that the recovery of muscle force was slower in the older adults. It was speculated that this could be due to an age related impairment in mammalian target of rapamycin complex 1 and/or satellite cell activation, possibly driven by immune senescence or "inflammageing", the age-related phenomenon characterised by a persistent elevation in systemic immune markers such as interleukin-6 and c-reactive protein (Calder et al., 2017; Doering et al., 2017; Doering, Reaburn, Phillips, \& Jenkins, 2016).

In addition to ensuring adequate energy intake (Minor, Heusinger, Melanson, Hamilton, \& Miller, 2012), one way to overcome the age-related decrease in MPS is to consume higher amounts of dietary protein following exercise. Studies have shown that older adults require higher amounts of protein $\left(\geq 0.40 \mathrm{~g} \cdot \mathrm{kg}^{-1}\right)$ than younger adults $\left(0.20-0.25 \mathrm{~g} \cdot \mathrm{kg}^{-1}\right)$ to maximally stimulate MPS (Katsanos, Kobayashi, Sheffield-Moore, Aarsland, \& Wolfe, 2006; Moore et al., 2015). This suggests that increasing post-exercise protein intake is a potential strategy for 
enhancing acute functional recovery and attenuating markers of exercise induced muscle damage (EIMD) in older adults.

To date, this has only been explored by one study (Doering et al., 2017). In this trial, when 8 masters triathletes ( $\sim 53$ years old) consumed 3 meals containing $0.60 \mathrm{~g} \cdot \mathrm{kg}^{-1}$ as opposed to 0.30 $\mathrm{g} \cdot \mathrm{kg}^{-1}$ of protein every $2 \mathrm{~h}$ following 30 minutes of downhill running, they reported less fatigue and were 5\% stronger when re-tested 8 hours later. However, it is unclear whether higher protein intake would have expedited recovery in the 48-h following the exercise task, which is when markers of EIMD like creatine kinase (CK) and muscle soreness (DOMS) tend to be greatest (Clarkson \& Sayers, 1999). Such changes could have important implications for muscle regeneration in older adults, which is shown to be impaired in the days following strenuous eccentric exercise or muscle injury (Lovering \& Brooks, 2014). Moreover, prolonged impairments in functional capacity could not only hinder exercise performance but could also affect tasks for daily living or deter older adults from performing exercise (Lovering $\&$ Brooks, 2014). Thus, interventions that could help to manage these symptoms in the days following exercise are desirable. Furthermore, Doering et al. (2017) did not measure changes in inflammation. Yet, one of the mechanisms by which increasing dietary protein intake might support muscle remodelling is by attenuating the acute inflammatory response associated with strenuous exercise (Kato et al., 2016; Kerasioti et al., 2013; Rowlands et al., 2016).

Consequently, the aim of this study was to assess whether a higher protein intake $(2.50$ $\mathrm{g} \cdot \mathrm{kg} \cdot \mathrm{day}^{-1}$ or $0.50 \mathrm{~g} \cdot \mathrm{kg}^{-1}$ per meal) for 2 days following strenuous exercise could attenuate inflammation and markers of muscle damage in recreationally trained adults over the age of 50. We hypothesized that a higher protein intake would lessen muscle soreness and inflammation following the exercise bout, and muscle function would be restored quicker in the subsequent $48 \mathrm{~h}$.

\section{Methods}

\section{Participants}

Eighteen male $(\mathrm{n}=10)$ and female $(\mathrm{n}=8)$ physically active $\geq 50$-year olds volunteered for this study (see Table 1 for physical characteristics). They were recruited by contacting local sports via email and social media. All participants were required to be performing $\geq 3 \mathrm{~h}$ per week of training for an endurance sport (running, swimming, rowing, cycling) to be eligible for this 
study. This was to ensure they would be able to complete the exercise task. None of the participants were competing at a national level or higher and all participants verbally confirmed they were not accustomed to the strenuous squatting exercise used in this study. Based on a similarly designed study (Bell, Stevenson, Davison, \& Howatson, 2016), we calculated (using G*Power) that at $80 \%$ power, and an $\alpha$ of 0.05 , at least 8 volunteers were required to detect a group difference of $10 \%$ in our primary outcome MIVC (7 SD units) post-exercise.

Participants completed a medical screening questionnaire and were excluded if they had a food allergy, had, or were using anti-inflammatory medications (within 1 month of participation), had received hormone replacement medications, had a previous history of cardiovascular or renal disease, or any other contraindication to the study procedures. Participants were required to avoid putative recovery interventions (e.g., massage) throughout the testing period. Institutional ethical approval was granted by the Newcastle University Ethics Committee; all participants read a participant information sheet before providing written informed consent prior to participation.

\section{Experimental design}

In a double blind, placebo-controlled, parallel groups design, participants were randomized to 1 of 2 experimental treatment arms: a higher protein group (HP) or a moderate protein group (MP). Participants were randomly stratified using sex and maximal isometric voluntary contraction (MIVC) scores as blocking factors. These scores were collected at a familiarisation session completed $\geq 5$ days prior to the main trials. To ensure blinding, the diets were prepared and prescribed by a registered sport nutritionist who was not involved in data collection. Participants were also not informed which diet they were receiving and were falsely led to believe that the differences in protein intake between the two diets was solely from the maltodextrin and whey protein supplements they received.

On the day of and the two days following the main trials, participants consumed a standardized breakfast (Oat and Honey cereal bar, Nature Valley, UK; energy, 192 kcal; carbohydrate, 27.1 g; fat, $7.2 \mathrm{~g}$; protein, $3.4 \mathrm{~g}) 30$ minutes prior to performing the baseline measures $(08: 00-$ 09:00). Water before testing was allowed ad-libitum. The baseline measures were collected in the following order: muscle soreness, Brief Assessment of Mood adapted (BAM+), a venous blood sample, and MIVC. Immediately following these measures, participants performed 140 weighted squats to induce muscle-damage. They were then provided with all meals and 
supplements for the following two days. Participants were instructed to avoid intense exercise in the 48-h leading up to the main trials and until all testing was completed.

\section{Muscle damaging exercise protocol}

To induce muscle damage, participants performed a total of 140 squats while wearing a vest containing $25 \%$ of their body mass $(\mathrm{kg})$. The squats were performed as 7 sets of 20 repetitions, separated by 2 minutes of passive recovery. Participants were required to squat down to an angle equivalent to $90^{\circ}$ of knee flexion for each repetition. This protocol was adapted from a previous study that found 140 squats, without additional weight, induced significant muscle damage in untrained young adults (Shimomura et al., 2010). The additional weight added in the present study was to try and augment muscle damage.

\section{Dietary Intervention}

In the $48 \mathrm{~h}$ post muscle damaging exercise, participants were provided with all of their food and fluids. Participants were allowed to consume water or non-caloric drinks ad libitum throughout this period, but all other foods and beverages were prohibited. Each feed post-testing ( 5 in total), was formulated to contain either $0.50 \mathrm{~g} \cdot \mathrm{kg} \cdot \mathrm{BM}^{-1}$ (HP diet) or $0.25 \cdot \mathrm{g} \cdot \mathrm{kg}^{-1}$ (MP diet) of protein, corresponding to 2.50 or $1.25 \mathrm{~g} \cdot \mathrm{kg} \cdot \mathrm{BM} \cdot \mathrm{day}^{-1}$ of protein, respectively. Participants had one feed immediately post-exercise and the further 4 feeds every $3 \mathrm{~h}$ (see Supplementary File for further details). The protein amounts were based on the current per meal recommendations for athletic populations (Moore et al., 2015). The daily energy macronutrient composition of the two diets is provided in Table 1. Further details on the diets are provided in a Supplementary File.

\section{Maximal isometric voluntary contraction}

As described previously (Clifford et al., 2017), MIVC was measured with a portable strain gauge (MIE Medical Research Ltd., Leeds, UK). Participants were seated upright and had a perspex gauze attached to a force transducer strapped to their ankle. After a countdown, participants were instructed to maximally extended their right knee flexor and hold for a 3 second contraction. The peak value $(\mathrm{N})$ from 3 maximal contractions (separated by a $60 \mathrm{~s}$ rest period) was used for analysis. The inter-day CV for this measure and procedure is $3.9 \%$ in our lab. 
Lower limb muscle soreness was measured subjectively with a $200 \mathrm{~mm}$ visual analogue scale (Clifford et al., 2017). Participants performed a squat to a 90-degree knee angle and drew a vertical line on a visual analogue scale labelled with 'no soreness' $(0 \mathrm{~mm})$ at one end and 'unbearably painful' at the other $(200 \mathrm{~mm})$. The line placement was measured with a ruler and recorded.

\section{Brief assessment of mood adapted}

The BAM+ is a measure of performance readiness and was scored by marking a vertical line on a $100 \mathrm{~mm}$ VAS between "not at all" and "extremely". The scores were calculated by subtracting the 4 positively associated questions by the 6 negatively associated questions. A full list of the included questions is available in Shearer et al. (Shearer et al., 2017).

\section{Blood sampling}

Venous blood samples were collected via venepuncture. At all 3 time points $(0,24$ and $48 \mathrm{~h}$ post-exercise), blood was drawn into a $10 \mathrm{ml}$ vacutainer for serum and a 10- and 4-ml vacutainer coated with di-potassium ethylene diamine tetra-acetic acid (EDTA). The $4 \mathrm{ml}$ EDTA vacutainer was transported to a local hospital for analysis of full blood counts. The remaining tubes were centrifuged at $3000 \mathrm{rpm}\left(4^{\circ} \mathrm{C}\right)$ for 10 minutes to separate the supernatant, which were subsequently aspirated into aliquots and stored in a $-80^{\circ}$ freezer for later analysis.

\section{Blood analysis}

Full blood cell counts were assessed with an automated haematology system (Sysmex XE2100 , Illinois, US). CV for this analysis is $<10 \%$. Creatine kinase (CK) and high sensitivity Creactive protein (hs-CRP) was measured in serum using an automated system based on an electrochemiluminescence method (Roche Modular, Roche Diagnostics, UK). CV for this analysis was $<5 \%$. Plasma interluekin-6 (IL-6), interleukin-1 $\beta$ (IL-1 $\beta$ ) and monocyte chemoattractant protein (MCP-1) were measured using commercially available ELISA kits (R and D systems, MN, US). Because $\sim 25 \%$ of the samples were below the detectable limit for IL-1 $\beta$ analysis results are not reported for this marker. CV for IL-6 and MCP-1 were 15 and $5 \%$, respectively.

\section{Statistical Analysis}


Data were analysed using SPSS (Version 24, SPSS, Armonk, NY). All data are expressed as means \pm standard deviation (SD); an $\alpha$ level of $\mathrm{P}<0.05$ was accepted to be statistically significant. Baseline values of muscle function, age, height, body mass and energy intake were assessed for group differences using an independent samples t-test. Between group differences in activity levels, carbohydrate, fat and protein intakes were analysed with Mann-Whitney U non-parametric test because they were not normally distributed ( $\mathrm{P}<0.05$ on the Shapiro-Wilk test). Dependent variables were analysed with a mixed model analysis of variance (ANOVA) with two group levels (HP and MP) and three repeated measures time-points $(0,24$ and $48 \mathrm{~h}$ post-exercise). Because leukocytes and eosinophils were significantly different between groups at $0 \mathrm{~h}$ these variables analysed as percentage change from baseline. Muscle soreness, IL-6, MCP-1 and eosinophils were not normally distributed and therefore logged transformed prior to analysis. If the ANOVA indicated a significant effect, post-hoc tests with Bonferroni corrections were performed to locate the specific differences. Where sphericity was significantly violated, Greenhouse-Geisser adjustments were used. Partial-eta2 ( $\eta$ 2) effect size statistics were considered small $(0.01-0.06)$, medium $(0.06-0.14)$ or large $(\geq 0.14)$ changes.

\section{Results}

There were no differences in the participant's physical characteristics, activity levels and energy intake between the two groups ( $\mathrm{P}>0.05$; Table 1). However, as expected, fat and carbohydrate intake were lower and protein intake higher in the HP group $(\mathrm{P}<0.05$; Table 1$)$.

MIVC were lower following muscle damaging exercise in both groups (time effect; $\mathrm{P}=0.001$, $\eta p 2: 0.421$; Figure 1A) but no interaction effects were present $(\mathrm{P}=0.822, \eta \mathrm{p} 2: 0.012)$. BAM+ reduced after exercise (time effect; $\mathrm{P}=0.049 ; \eta \mathrm{p} 2$ : 0.172; Figure $1 \mathrm{C}$ ); however, there was no interaction effect ( $\mathrm{P}=0.363 ; \eta p 2: 0.058)$. Muscle soreness increased in the days following exercise, peaking at $24 \mathrm{~h}$ post in the MP group and $48 \mathrm{~h}$ post in the HP group (time effect; $\mathrm{P}=$ 0.005; १р2: 0.282); however, no interaction effects were found $(\mathrm{P}=0.585 ; \eta \mathrm{p} 2: 0.083$; Figure 1B).

Monocytes and lymphocytes were decreased in the days after exercise, and eosinophils increased $24 \mathrm{~h}$ post, but total leukocyte count, neutrophils and basophils remained unchanged pre to post-exercise (Table 2). There were no group differences in any of the haematological markers (Table 2). CK did not increase after exercise (time effect $P=0.359, \eta p 2: 0.062$ ) and there were no group differences at any time point (interaction effect; $\mathrm{P}=0.779, \eta p 2$ : 0.006; 
Figure 1D). hs-CRP displayed no time $(\mathrm{P}=0.783, \eta \mathrm{p} 2: 0.015)$ or interaction effects $(\mathrm{P}=0.905$, $\eta p 2: 0.006$; Figure 1F), neither did IL-6 (time: $\mathrm{P}=0.497$, $ү$ 2: 0.039; interaction: $\mathrm{P}=0.159$, $\eta p 2: 0.133$; Figure 1E) or MCP-1 (time: $\mathrm{P}=0.772$, $\eta \mathrm{p} 2$ : 0.009; interaction: $\mathrm{P}=0.685, \eta \mathrm{p} 2$ : 0.016 ; Figure $1 \mathrm{G})$.

\section{Discussion}

In contrast to our hypothesis, a higher protein diet for 2 days following strenuous exercise was no more effective than a moderate protein diet for attenuating inflammation and markers of EIMD in active older adults.

Only one other study has examined the effects of high protein intake on recovery from strenuous exercise in older adults. In contrast to the present study, they found feeding high amounts of dietary protein in the post-exercise period enhanced the recovery of muscle function in 8 master's triathletes (Doering et al., 2017) The reason for the disparate findings between the current and previous study is not overtly clear but it could be related to the amount and timing of protein intake and/or when the measures were collected. For example, Doering and colleagues fed their participants higher amounts of protein $\left(0.60 \mathrm{~g} \cdot \mathrm{kg} \cdot{ }^{-1} \mathrm{vs} .0 .50 \mathrm{~g} \cdot \mathrm{kg} \cdot{ }^{-1}\right)$ in the post-exercise period but did not monitor recovery for longer than $8 \mathrm{~h}$ post-exercise. By contrast, in the present study, the dietary control and collection of outcome measures continued for 48 $\mathrm{h}$ post-exercise. As such, it could be that; 1) the $0.50 \mathrm{~g} \cdot \mathrm{kg}^{-1}$ of protein we provided at each feed was not sufficient to affect myofibrillar recovery processes/inflammation in our participants or that; 2) higher than the recommended amounts of protein are only beneficial when recovery times are short (e.g., $\leq 8 \mathrm{~h}$ ). The fact that we did not measure markers of EIMD at $8 \mathrm{~h}$ post-exercise to compare with Doering et al. (2017) is an acknowledged limitation of this study. Clearly, more studies are needed to determine if higher than recommended protein intakes can expedite recovery in older active adults.

Although there was a decrease in MIVC and an increase in muscle soreness following exercise, none of the other markers typically associated with EIMD - including the pro-inflammatory markers (e.g., neutrophils, IL-6, MCP-1) and CK, were significantly altered 24 and $48 \mathrm{~h}$ following the exercise bout. CK was also not altered in a previous study that used an identical protocol in untrained participants but without the added weight (Shimomura et al., 2010). This study observed less muscle soreness than we did, but greater decrements in muscle function, possibly due to the fact the participants were sedentary. This would suggest that the exercise bout, while novel to the participants and encompassing a large number of eccentric muscle 
contractions, only induced mild muscle-damage in our participants and, therefore, despite their age, the systemic inflammatory response was minor (Paulsen, Mikkelsen, Raastad, \& Peake, 2012). It is possible that the minor changes in the markers of muscle-damage limited our ability to detect small group differences or rendered the high protein diet less effective. With regards to the latter point, it would be reasonable to assume that any intervention aiming to influence recovery processes after exercise would be more effective if the symptoms of muscle damage are marked and prolonged. Perhaps if the participants were less physically active or over the age of 65, which is when impairments in muscle regeneration accelerate further (Cruz-Jentoft et al., 2010; Kamandulis et al., 2017), muscle damage and inflammation would have been greater. With that said, we did anticipate that we would see larger changes in these markers, given that Doering et al. (Doering, Jenkins, et al., 2016) found MPS to be lower in trained triathletes of similar age to our volunteers, and other studies have found markers of muscle damage to be exacerbated in adults 50 - 65 years of age (Lavender \& Nosaka, 2006; PloutzSnyder, Giamis, Formikell, \& Rosenbaum, 2001).

It should also be highlighted that the magnitude of changes to neuromuscular and soreness variables observed in this study are akin to those we have seen after competitive events such as a marathon (Clifford et al., 2017) or soccer match (Abbott, Brett, Cockburn, \& Clifford, 2019). As such, the changes in muscle function and muscle soreness in the present study are likely a better reflection of the changes observed after more ecologically valid forms of exercise, than the changes observed after most lab-based exercise protocols that typically result in severe myofibrilar disruption, evoking symptoms that last for several weeks (Paulsen et al., 2012).

It is important to note that, in general, the benefits of increasing dietary protein on acute muscle function recovery remains equivocal, irrespective of age. Indeed, a systematic review of the literature suggested that while, in theory, increasing protein intake to augment MPS should enhance myofibrillar remodelling and, ostensibly, the recovery of muscle function, there is little high-quality research to support this assumption (Pasiakos, Lieberman, \& McLellan, 2014). Indeed, it has been proposed by others that the turnover of intramuscular proteins is probably too slow to significantly influence the acute restoration of muscle contractile function following strenuous exercise (Farup et al., 2014; Owens, Twist, Cobley, Howatson, \& Close, 2019). With that said, ingesting whey protein post-exercise, as in this study, can also attenuate inflammation (Kato et al., 2016; Kerasioti et al., 2013; Rowlands et al., 2016) and increase muscle satellite cell activity (Farup et al., 2014), both of which might positively influence acute 
functional recovery following exercise (Owens et al., 2019). Thus, an increase in MPS and protein turnover are unlikely to be the only mechanisms by which dietary protein could ameliorate symptoms of muscle damage. Future studies examining the effects of protein intake of recovery, irrespective of age, should aim to control pre and post-exercise dietary intake, but also, where possible, take measures of MPS, satellite cell activation and inflammation alongside measures of functional recovery like isometric strength and muscle soreness.

A limitation of this study is that, due to ethical constraints, we did not measure MPS to see if the HP diet augmented muscle FSR in the 48-h following exercise. However, as summarised by Moore and colleagues, the fact that several studies show higher amounts of protein $(\geq 0.40$ $\mathrm{g} \cdot \mathrm{kg} \cdot \mathrm{meal}^{-1}$ ) optimises MPS in older adults, lends support to this assertion (Moore et al., 2015). Due to funding constraints we also limited our observations to $48 \mathrm{~h}$ post-exercise when some variables had not completely returned to baseline. We suggest that future studies continue monitoring recovery for $72-96 \mathrm{~h}$ post-exercise or until markers are restored to baseline levels to ensure they do not miss any differences that might arise during the later stages of recovery. Similarly, by not taking blood samples $<24$ h post exercise, we likely missed peak increases in the inflammatory cytokines measured and acknowledge this is a limitation of the current study. A key strength of this study is the strict dietary control, a design aspect often neglected in protein and exercise recovery research, and probably a key reason for the equivocal findings to date (Pasiakos et al., 2014). Nonetheless, we acknowledge that not standardizing diet in the 48 $\mathrm{h}$ prior to exercise could have influenced the findings and recommend future studies take this into consideration.

\section{Conclusion}

In conclusion, a higher protein diet $\left(2.5 \mathrm{~g} \cdot \mathrm{kg} \cdot \mathrm{day}^{-1}\right)$ for 2 days did not attenuate markers of muscle damage or inflammation following unaccustomed exercise in older ( $\sim 57$ years) active adults. This could be due to the fact muscle damage was only mild. Future studies should utilise exercise protocols that elicit greater levels of muscle damage.

\section{Decelerations}

\section{Funding}

Funding for the cytokine assay kits was provided by the British Association of Sport and Exercise Sciences (BASES) from a grant that was awarded to Tom Clifford. The organisation had no input on the design, analysis and interpretation of the results. 


\section{Conflict of interest}

336 The authors declare no conflicts of interest.

337

338

339

340

341

342

\section{Author contributions}

The study was designed by TC, EH and EJS; data were collected and analysed by TC, EH, $\mathrm{KBD}, \mathrm{GT}$, JS and KS; data interpretation and manuscript preparation were undertaken by TC, JS, EH, EJS, KBD, GT, KS. All authors approved the final version of the paper.

\section{References list}

Abbott, W., Brett, A., Cockburn, E., \& Clifford, T. (2019). Presleep casein protein ingestion: Acceleration of functional recovery in professional soccer players. International Journal of Sports Physiology and Performance. https://doi.org/10.1123/ijspp.2018-0385

Bell, P. G., Stevenson, E., Davison, G. W., \& Howatson, G. (2016). The effects of montmorency tart cherry concentrate supplementation on recovery following prolonged, intermittent exercise. Nutrients. https://doi.org/10.3390/nu8070441

Brisswalter, J., \& Nosaka, K. (2013). Neuromuscular factors associated with decline in longdistance running performance in master athletes. Sports Medicine. https://doi.org/10.1007/s40279-012-0006-9

Calder, P. C., Bosco, N., Bourdet-Sicard, R., Capuron, L., Delzenne, N., Doré, J., ... Visioli, F. (2017). Health relevance of the modification of low grade inflammation in ageing (inflammageing) and the role of nutrition. Ageing Research Reviews. https://doi.org/10.1016/j.arr.2017.09.001

Clarkson, P. M., \& Sayers, S. P. (1999). Etiology of exercise-induced muscle damage. Canadian Journal of Applied Physiology. https://doi.org/10.1139/h99-020

Clifford, T., Allerton, D. M., Brown, M. A., Harper, L., Horsburgh, S., Keane, K. M., ... Howatson, G. (2017). Minimal muscle damage after a marathon and no influence of beetroot juice on inflammation and recovery. Applied Physiology, Nutrition and Metabolism. https://doi.org/10.1139/apnm-2016-0525

Cruz-Jentoft, A. J., Baeyens, J. P., Bauer, J. M., Boirie, Y., Cederholm, T., Landi, F., ... Zamboni, M. (2010). Sarcopenia: European consensus on definition and diagnosis: Report of the European Working Group on Sarcopenia in Older People. Age and Ageing. 
365

Doering, T. M., Jenkins, D. G., Reaburn, P. R., Borges, N. R., Hohmann, E., \& Phillips, S. M. (2016). Lower Integrated Muscle Protein Synthesis in Masters Compared with Younger Athletes. Medicine and Science in Sports and Exercise. https://doi.org/10.1249/MSS.0000000000000935

Doering, T. M., Reaburn, P. R., Borges, N. R., Cox, G. R., \& Jenkins, D. G. (2017). The effect of higher than recommended protein feedings post-exercise on recovery following downhill running in masters triathletes. International Journal of Sport Nutrition and Exercise Metabolism. https://doi.org/10.1123/ijsnem.2016-0079

Doering, T. M., Reaburn, P. R., Phillips, S. M., \& Jenkins, D. G. (2016). Postexercise dietary protein strategies to maximize skeletal muscle repair and remodeling in masters endurance athletes: A review. International Journal of Sport Nutrition and Exercise Metabolism. https://doi.org/10.1123/ijsnem.2015-0102

Easthope, C. S., Hausswirth, C., Louis, J., Lepers, R., Vercruyssen, F., \& Brisswalter, J. (2010). Effects of a trail running competition on muscular performance and efficiency in well-trained young and master athletes. European Journal of Applied Physiology. https://doi.org/10.1007/s00421-010-1597-1

Farup, J., Rahbek, S. K., Knudsen, I. S., De Paoli, F., Mackey, A. L., \& Vissing, K. (2014). Whey protein supplementation accelerates satellite cell proliferation during recovery from eccentric exercise. Amino Acids. https://doi.org/10.1007/s00726-014-1810-3

Hyldahl, R. D., \& Hubal, M. J. (2014). Lengthening our perspective: Morphological, cellular, and molecular responses to eccentric exercise. Muscle and Nerve. https://doi.org/10.1002/mus.24077

Kamandulis, S., De Souza Leite, F., Hernández, A., Katz, A., Brazaitis, M., Bruton, J. D., ... Westerblad, H. (2017). Prolonged force depression after mechanically demanding contractions is largely independent of $\mathrm{Ca} 2+$ and reactive oxygen species. FASEB Journal. https://doi.org/10.1096/fj.201700019R

Kato, H., Miura, K., Nakano, S., Suzuki, K., Bannai, M., \& Inoue, Y. (2016). Leucineenriched essential amino acids attenuate inflammation in rat muscle and enhance muscle repair after eccentric contraction. Amino Acids. https://doi.org/10.1007/s00726-016- 
395

396

397

400

401

402

403

404

405

406

407

408

409

410

411

412

413

414

415

416

417

Katsanos, C. S., Kobayashi, H., Sheffield-Moore, M., Aarsland, A., \& Wolfe, R. R. (2006). A high proportion of leucine is required for optimal stimulation of the rate of muscle protein synthesis by essential amino acids in the elderly. American Journal of Physiology - Endocrinology and Metabolism. https://doi.org/10.1152/ajpendo.00488.2005

Kerasioti, E., Stagos, D., Jamurtas, A., Kiskini, A., Koutedakis, Y., Goutzourelas, N., ... Kouretas, D. (2013). Anti-inflammatory effects of a special carbohydrate-whey protein cake after exhaustive cycling in humans. Food and Chemical Toxicology. https://doi.org/10.1016/j.fct.2013.01.023

Lavender, A. P., \& Nosaka, K. (2006). Responses of old men to repeated bouts of eccentric exercise of the elbow flexors in comparison with young men. European Journal of Applied Physiology. https://doi.org/10.1007/s00421-006-0224-7

Lovering, R. M., \& Brooks, S. V. (2014). Eccentric exercise in aging and diseased skeletal muscle: Good or bad? Journal of Applied Physiology. https://doi.org/10.1152/japplphysiol.00174.2013

Minor, B. D., Heusinger, D. E., Melanson, E. L., Hamilton, K. L., \& Miller, B. F. (2012). Energy balance changes the anabolic effect of postexercise feeding in older individuals. Journals of Gerontology - Series A Biological Sciences and Medical Sciences. https://doi.org/10.1093/gerona/gls080

Moore, D. R., Churchward-Venne, T. A., Witard, O., Breen, L., Burd, N. A., Tipton, K. D., \& Phillips, S. M. (2015). Protein ingestion to stimulate myofibrillar protein synthesis requires greater relative protein intakes in healthy older versus younger men. Journals of Gerontology - Series A Biological Sciences and Medical Sciences. https://doi.org/10.1093/gerona/glu103

Owens, D. J., Twist, C., Cobley, J. N., Howatson, G., \& Close, G. L. (2019). Exerciseinduced muscle damage: What is it, what causes it and what are the nutritional solutions? European Journal of Sport Science. https://doi.org/10.1080/17461391.2018.1505957

Pasiakos, S. M., Lieberman, H. R., \& McLellan, T. M. (2014). Effects of protein supplements 
on muscle damage, soreness and recovery of muscle function and physical performance:

Paulsen, G., Mikkelsen, U. R., Raastad, T., \& Peake, J. M. (2012). Leucocytes, cytokines and satellite cells: What role do they play in muscle damage and regeneration following eccentric exercise? Exercise Immunology Review.

Ploutz-Snyder, L. L., Giamis, E. L., Formikell, M., \& Rosenbaum, A. E. (2001). Resistance training reduces susceptibility to eccentric exercise-induced muscle dysfunction in older women. Journals of Gerontology - Series A Biological Sciences and Medical Sciences. https://doi.org/10.1093/gerona/56.9.B384

Rowlands, D. S., Nelson, A. R., Raymond, F., Metairon, S., Mansourian, R., Clarke, J., ... Phillips, S. M. (2016). Protein-leucine ingestion activates a regenerative inflammomyogenic transcriptome in skeletal muscle following intense endurance exercise. Physiological Genomics. https://doi.org/10.1152/physiolgenomics.00068.2015

Shearer, D. A., Sparkes, W., Northeast, J., Cunningham, D. J., Cook, C. J., \& Kilduff, L. P. (2017). Measuring recovery: An adapted Brief Assessment of Mood (BAM+) compared to biochemical and power output alterations. Journal of Science and Medicine in Sport. https://doi.org/10.1016/j.jsams.2016.09.012

Shimomura, Y., Inaguma, A., Watanabe, S., Yamamoto, Y., Muramatsu, Y., Bajotto, G., ... Mawatari, K. (2010). Branched-chain amino acid supplementation before squat exercise and delayed-onset muscle soreness. International Journal of Sport Nutrition and Exercise Metabolism. https://doi.org/10.1123/ijsnem.20.3.236

Warren, G. L., Ingalls, C. P., Lowe, D. A., \& Armstrong, R. B. (2002). What mechanisms contribute to the strength loss that occurs during and in the recovery from skeletal muscle injury? Journal of Orthopaedic and Sports Physical Therapy. https://doi.org/10.2519/jospt.2002.32.2.58 
Table 1. Participant's physical characteristics and daily dietary intakes in the $48 \mathrm{~h}$ following 454 muscle damaging exercise.

\begin{tabular}{|c|c|c|}
\hline & HP & MP \\
\hline \multicolumn{3}{|l|}{ Physical characteristics } \\
\hline $\operatorname{Sex}($ no. $M / F)$ & $5 / 4$ & $5 / 4$ \\
\hline Age (years) & $57 \pm 4$ & $56 \pm 4$ \\
\hline Mass (kg) & $73.6 \pm 10.8$ & $71.0 \pm 9.3$ \\
\hline Height (m) & $1.73 \pm 7.1$ & $1.73 \pm 5.9$ \\
\hline Activity levels $\left(\mathrm{h} \cdot \mathrm{wk}^{-1}\right)$ & $8.5 \pm 4.7$ & $7.7 \pm 2.5$ \\
\hline $\operatorname{MIVC}(\mathrm{N})$ & $385 \pm 124$ & $408 \pm 151$ \\
\hline \multicolumn{3}{|l|}{ Dietary intake } \\
\hline \multicolumn{3}{|l|}{ Energy } \\
\hline $\mathrm{Kcal} \cdot \mathrm{day}^{-1}$ & $2464.85 \pm 321.01$ & $2425.86 \pm 266.45$ \\
\hline $\mathrm{Kcal} \cdot \mathrm{kg} \cdot \mathrm{day}^{-1}$ & $33.55 \pm 0.58$ & $34.34 \pm 0.85$ \\
\hline \multicolumn{3}{|l|}{ Protein* } \\
\hline $\mathrm{g} \cdot \mathrm{day}^{-1}$ & $184.05 \pm 26.90$ & $88.69 \pm 57$ \\
\hline $\mathrm{g} \cdot \mathrm{kg} \cdot \mathrm{day}^{-1}$ & $2.50 \pm 0.00$ & $1.25 \pm 0.00$ \\
\hline \multicolumn{3}{|l|}{ Carbohydrate* } \\
\hline $\mathrm{g} \cdot \mathrm{day}^{-1}$ & $284.60 \pm 41.60$ & $308.83 \pm 40.28$ \\
\hline $\mathrm{g} \cdot \mathrm{kg} \cdot \mathrm{day}^{-1}$ & $3.86 \pm 7.02$ & $4.35 \pm 9.81$ \\
\hline \multicolumn{3}{|l|}{ Fat* } \\
\hline $\mathrm{g} \cdot \mathrm{day}^{-1}$ & $29.27 \pm 2.68$ & $52.52 \pm 3.93$ \\
\hline $\mathrm{g} \cdot \mathrm{kg} \cdot \mathrm{day}^{-1}$ & $0.40 \pm 0.23$ & $0.74 \pm 0.49$ \\
\hline
\end{tabular}


Table 2. Heamotological markers pre $(0 \mathrm{~h}), 24$ and $48 \mathrm{~h}$ post-exercise in the high protein $(\mathrm{HP})$ and mdoerate protein (MP) groups. 465

\begin{tabular}{|c|c|c|c|c|c|}
\hline & $\mathbf{O} \mathbf{h}$ & $+24 \mathrm{~h}$ & $+48 \mathrm{~h}$ & $\begin{array}{l}P \text { time } \\
\text { effect* }\end{array}$ & $\begin{array}{c}P \text { interaction } \\
\text { effect } *\end{array}$ \\
\hline \multicolumn{6}{|c|}{ Leukocytes $\left(10^{* 9}\right.$ Cells $\left.\cdot L^{-1}\right)$} \\
\hline $\mathrm{HP}$ & $5.67 \pm 0.90$ & $5.71 \pm 1.15$ & $5.41 \pm 0.78$ & \multirow{2}{*}{$0.322(0.068)$} & \multirow{2}{*}{$0.710(0.20)$} \\
\hline MP & $4.54 \pm 1.09$ & $4.60 \pm 1.15$ & $4.54 \pm 1.21$ & & \\
\hline \multicolumn{6}{|c|}{ Neutrophils $\left(10 * 9\right.$ Cells $\left.\cdot L^{-1}\right)$} \\
\hline HP & $3.18 \pm 0.85$ & $3.38 \pm 1.09$ & $3.19 \pm 0.86$ & \multirow{2}{*}{$0.349(0.60)$} & \multirow{2}{*}{$0.600(0.24)$} \\
\hline MP & $2.46 \pm 0.96$ & $2.64 \pm 0.95$ & $2.65 \pm 1.07$ & & \\
\hline \multicolumn{6}{|c|}{ Lymphocytes $\left(10^{* 9}\right.$ Cells $\left.\cdot L^{-1}\right)$} \\
\hline HP & $1.74 \pm 0.41$ & $1.59 \pm 0.35^{* *}$ & $1.52 \pm 0.29 * *$ & \multirow{2}{*}{$0.001(0.408)$} & \multirow{2}{*}{$0.486(0.044)$} \\
\hline MP & $1.47 \pm 0.12$ & $1.40 \pm 0.10^{* *}$ & $1.33 \pm 0.10^{* *}$ & & \\
\hline \multicolumn{6}{|c|}{ Monocytes $\left(10 * 9\right.$ Cells $\left.\cdot \mathbf{L}^{-1}\right)$} \\
\hline HP & $0.50 \pm 0.11$ & $0.30 \pm 0.23 * *$ & $0.46 \pm 0.11$ & \multirow{2}{*}{$0.001(0.601)$} & \multirow{2}{*}{$0.381(0.053)$} \\
\hline MP & $0.45 \pm 0.13$ & $0.15 \pm 0.14^{* *}$ & $0.39 \pm 0.12$ & & \\
\hline \multicolumn{6}{|c|}{ Eosonphils $\left(10 * 9\right.$ Cells $\left.\cdot \mathbf{L}^{-1}\right)$} \\
\hline HP & $0.21 \pm 0.08$ & $0.39 \pm 0.10 * *$ & $0.20 \pm 0.10$ & \multirow{2}{*}{$0.001(0.693)$} & \multirow{2}{*}{$0.133(0.129)$} \\
\hline MP & $0.13 \pm 0.07$ & $0.38 \pm 0.12 * *$ & $0.14 \pm 0.07$ & & \\
\hline \multicolumn{6}{|c|}{ Basophils $\left(10 * 9\right.$ Cells $\left.\cdot L^{-1}\right)$} \\
\hline HP & $0.04 \pm 0.01$ & $0.04 \pm 0.01$ & $0.04 \pm 0.01$ & \multirow{2}{*}{$0.668(0.025)$} & \multirow{2}{*}{$0.668(0.025)$} \\
\hline MP & $0.04 \pm 0.01$ & $0.03 \pm 0.02$ & $0.04 \pm 0.02$ & & \\
\hline
\end{tabular}

$466 \quad *$ Number in parenthesis is $\eta p^{2}$ effect sizes. ${ }^{* *}$ Different to baseline $(\mathrm{P}<0.05) . n=9$ per group. 
469 Figure 1: Changes in maximal isometric voluntary contractions (MIVC), Brief Assessment of 470 Mood Adapted (BAM+), muscle soreness, creatine kinase (CK), interleukin-6 (IL-6), high471 sensitivity C-reactive protein (hs-CRP) and monocyte chemotactic protein-1 (MCP-1) pre472 exercise $(0 \mathrm{~h}), 24$ and $48 \mathrm{~h}$ post exercise after a high protein (HP) or moderate protein diet 473 (MP). *Denotes time effect, $\mathrm{P}<0.05$. MIVC, BAM + and muscle soreness are presented as 474 change from baseline for illustrative purposes.

475 
MP $\square$ HP
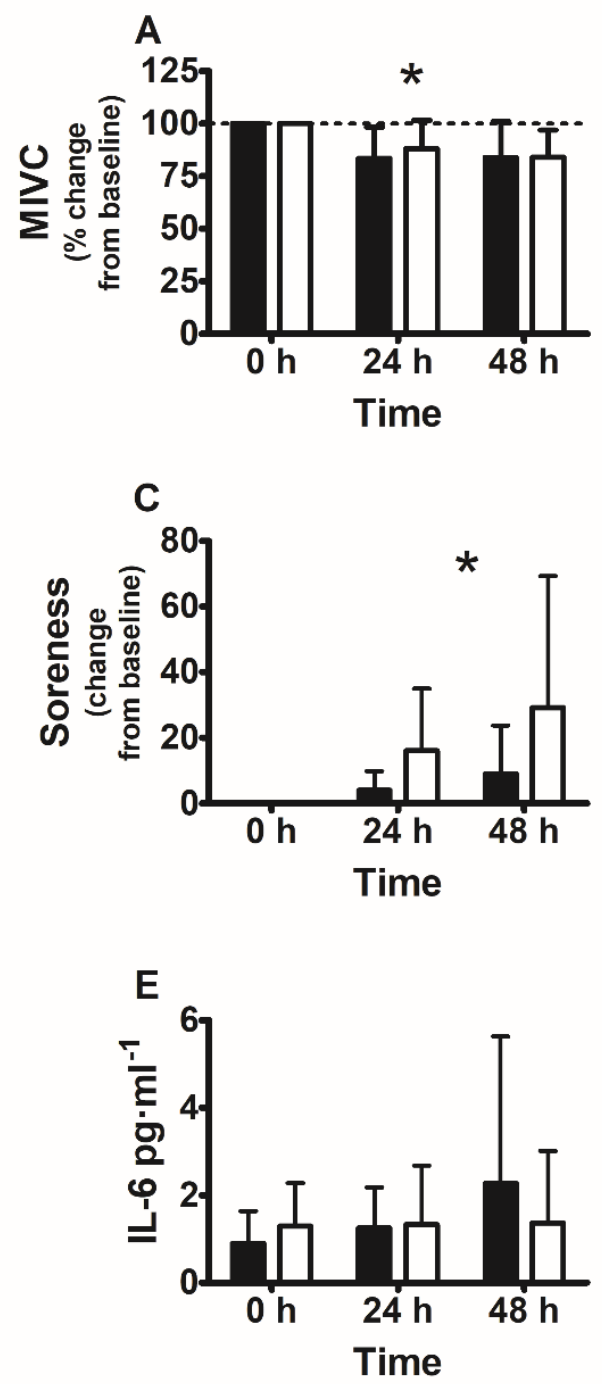
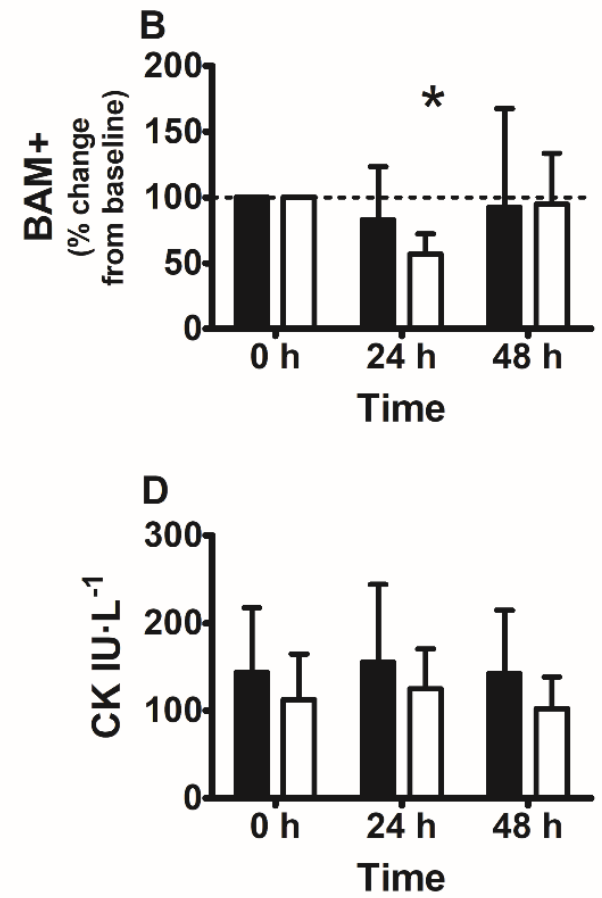

F

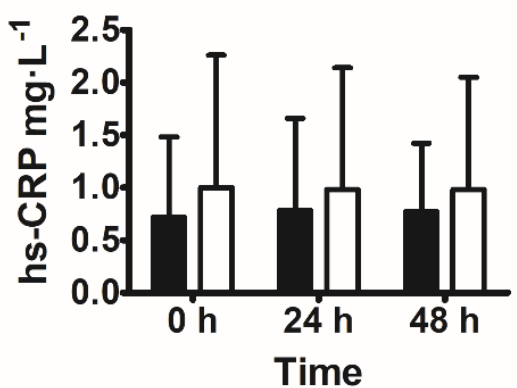

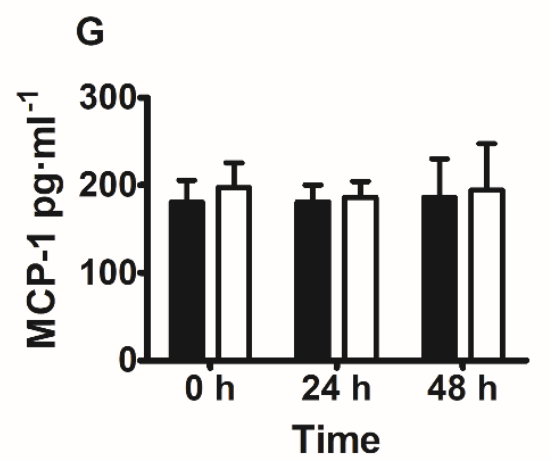




\section{Online supplementary material}

482 Both diets provided a small breakfast before testing, followed by 3 meals and two liquid boluses. Each feed post-testing ( 5 in total), was formulated to contain either $0.50 \mathrm{~g} \cdot \mathrm{kg} \cdot \mathrm{BM}^{-1}$ 484 (HP diet) or $0.25 \cdot \mathrm{g} \cdot \mathrm{kg}^{-1}$ (MP diet) of protein, corresponding to 2.50 or $1.25 \mathrm{~g} \cdot \mathrm{kg} \cdot \mathrm{BM} \cdot \mathrm{day}^{-1}$ of 485 protein, respectively. The protein amounts were based on the current per meal 486 recommendations for athletic populations (Moore et al., 2015). For example, it is currently 487 recommended that $0.25 \cdot \mathrm{g} \cdot \mathrm{kg}^{-1}$ of protein is required at each meal to optimise MPS in healthy 488 younger adults (Moore, 2015). This amount was then doubled for the experimental HP diet, 489 ensuring that post-exercise and each subsequent feed provided the $\geq 0.40 \mathrm{~g} \cdot \mathrm{kg} \cdot \mathrm{BM}^{-1}$ postulated 490 to optimise daily MPS in older athletes (Doering, Reaburn, Phillips, \& Jenkins, 2016; Moore 491 et al., 2015). The food stuffs provided were identical for both diets (tuna, chicken, pasta, cous 492 cous, mayonnaise, whey protein and maltodextrin) with the exception of additional olive oil in 493 the MP diet to match them for energy content.

494 To match the HP and MP diets for energy, the MP diet contained more carbohydrates and fats 495 (see Table 1 in manuscript). The specific foods were the same, but the ratios of each were 496 altered to get the desired energy intake. The overall energy content of the diet was 497 individualised for each participant and calculated to cover the energy needs for a moderate 498 level of activity using the Harris-Benedict equation (Harris \& Benedict, 1918). To ensure an 499 even distribution of protein intake throughout the day - and therefore facilitate optimal 500 conditions for MPS (Areta et al., 2013), participants were instructed to consume each bolus 2 $501-4 \mathrm{~h}$ apart. The foods were the same for each diet, and therefore the amino acid quality and 502 distribution was the same in each condition. Compliance with the diet was confirmed verbally 503 at each visit. 